\title{
Ambiguous relation between physical workload and low back pain: a twin control study
}

\author{
J Hartvigsen, K O Kyvik, C Leboeuf-Yde, S Lings, L Bakketeig
}

Occup Environ Med 2003;60:109-114

See end of article for authors' affiliations

.....................

Correspondence to: Dr J Hartvigsen, Nordic

Institute of Chiropractic and

Clinical Biomechanics,

Klosterbakken 20,

DK-5000 Odense C,

Denmark;

j.hartvigsen@nikkb.dk

Accepted 5 June 2002

\begin{abstract}
Aims: To examine the association between self reported physical workload and low back pain (LBP) in younger twins. To investigate whether genetic factors interact with physical workload in relation to LBP. Methods: A twin control study was performed within a population based twin register using 1910 complete monozygotic (MZ) and same sexed dizygotic (DZ) twin pairs aged 25-42 and discordant for LBP. LBP in the affected twins was divided into two groups: "LBP for $\leqslant 30$ days during the past year", and "LBP for $>30$ days during the past year". Physical workload was divided into four categories: "sitting", "sitting/walking", "light physical", and "heavy physical". Data were analysed in a matched design using conditional logistic regression. MZ and DZ twins were analysed separately and together in order to determine possible genetic influences in relation to physical workload and LBP.

Results: Statistically significant graded relations were found for increasing workload and LBP of longer duration but not for LBP of shorter duration ( $\leqslant 30$ days during the past year). In both LBP groups the "sitting" and "sitting/walking" groups were not statistically different. MZ and DZ twins did not differ significantly with respect to LBP in the various workload groups.

Conclusions: There is evidence for a dose-response relation between physical workload and LBP of longer duration. Attention to clinically relevant subgroups based on duration, for example, is necessary in epidemiological studies dealing with LBP. Physical workload might be more important than genetic factors in LBP.
\end{abstract}

ow back pain (LBP) is an enormous public health problem in developed countries. In the United Kingdom alone the - combined direct and indirect costs associated with LBP are estimated to be over $£ 12$ billion annually. ${ }^{1}$ This is more than the estimated costs of lower respiratory tract infections, Alzheimer's disease, stroke, diabetes, multiple sclerosis, and epilepsy combined. ${ }^{1}$ Considerable research efforts have been devoted to determining potential risk factors in order to identify possible preventive measures. Physical workload, a suspected risk factor, has been investigated extensively in relation to LBP over the past three decades. We are now beginning to see a pattern of heavier physical work as being hazardous for the low back and sedentary work as having either a neutral or protective effect in relation to LBP. ${ }^{23}$ However, the evidence is not completely consistent and many studies are generally considered to be of low methodological quality. $^{2-4}$

Identification of different varieties or subgroups of LBP was listed as a primary research priority by the Second International Forum for Primary Care Research on Low Back Pain in 1998. ${ }^{5}$ In 2001 Leboeuf-Yde and Manniche proposed that probably embedded in the term "low back pain" were several, yet unidentified, subentities, some of which might be identified through their selective association with risk factors ${ }^{6}$ - that is, excessive body weight is associated with recurrent or longer lasting LBP, but not with shorter or fewer attacks. ${ }^{7}$ It is possible that inconsistencies between studies dealing with physical workplace exposures in relation to LBP might be caused by lack of attention to such subentities.

Twin studies provide a special research methodology which, as well as assessing the relative contributions of genetic and environmental factors to a disease, may also be used to examine environmental risk factors in twin pairs discordant for that disease trait. ${ }^{8}$ This so called "twin control method" can provide information about the way genes and relevant environmental factors interact. ${ }^{9}$ We performed such a twin control study nested within a population based twin study. Our aims were to examine the pattern of association between self reported physical work load and LBP in workers aged 25-42, and to investigate whether the associations differ depending on the duration of LBP. Furthermore we wanted to investigate whether genetic factors influence this relation.

\section{MATERIALS AND METHODS \\ Subjects}

This study was based on the "young cohort" of the Danish Twin Register established in 1991. In 1994, a questionnaire survey dealing with a large number of health, lifestyle, and occupational factors was performed. The subsequent database comprises 29433 twin individuals (11992 complete pairs) born between 1 January 1953 and 31 December 1982. The establishment and characteristics of this cohort have been described in detail elsewhere. ${ }^{10}$

The present study was restricted to birth cohorts 1953-68 aged 25-42 at the time of data collection. Of the 13592 twins (6796 pairs) born 1953-68, 8776 (4388 pairs) were either monozygotic (MZ) or same sexed dizygotic (DZ) pairs. For the analysis of risk factors for LBP, the informative twins were the twin pairs discordant for the disease trait. In this sample 1910 complete pairs (3820 individuals) were discordant with respect to LBP status, meaning that one twin reported LBP within the past year and the co-twin did not (table 1).

\section{Variables}

LBP was assessed by asking participants how many days they had experienced trouble (pain, tenderness, stiffness, or other trouble) in the lowest part of their back during the preceding year. The question was accompanied by a drawing showing a person from behind with the low back area clearly shaded. The

Abbreviations: DZ, dizygotic; LBP, low back pain; MZ, monozygotic 
Table 1 Distribution of sample with respect to gender, age, LBP, and physical workload

\begin{tabular}{|c|c|c|c|}
\hline Variable & $\begin{array}{l}M Z \text { twins } \\
(n=1420)\end{array}$ & $\begin{array}{l}\text { DZ twins } \\
(n=2400)\end{array}$ & $\begin{array}{l}M Z+D Z \text { twins } \\
(n=3820)\end{array}$ \\
\hline \multicolumn{4}{|l|}{ Gender } \\
\hline Male (\%) & 44 & 44 & 44 \\
\hline Female $(\%)$ & 56 & 56 & 56 \\
\hline Mean age, years (SD) & $33(4.47)$ & $33(4.42)$ & $33(4.45)$ \\
\hline \multicolumn{4}{|c|}{ Outcome variable: low back pain during past year } \\
\hline \multicolumn{4}{|l|}{ Cases } \\
\hline Any LBP in past year (\%) & 100 & 100 & 100 \\
\hline LBP $\leqslant 30$ days (short) (\%) & 79 & 78 & 78 \\
\hline LBP $>30$ days (long) (\%) & 21 & 22 & 22 \\
\hline \multicolumn{4}{|l|}{ Controls } \\
\hline No LBP in past year (\%) & 100 & 100 & 100 \\
\hline \multicolumn{4}{|c|}{ Potential risk indicators (cases and controls): physical work load } \\
\hline Sitting only $(\%)$ & 26 & 24 & 24 \\
\hline Sitting and walking (\%) & 27 & 26 & 27 \\
\hline Light physical (\%) & 31 & 35 & 33 \\
\hline Heavy physical (\%) & 15 & 14 & 15 \\
\hline Missing (\%) & 1 & 1 & 1 \\
\hline
\end{tabular}

Table 2 Percentage of sample in 10 occupational groups according to the DISCO-88 classification and physical workload in the various groups

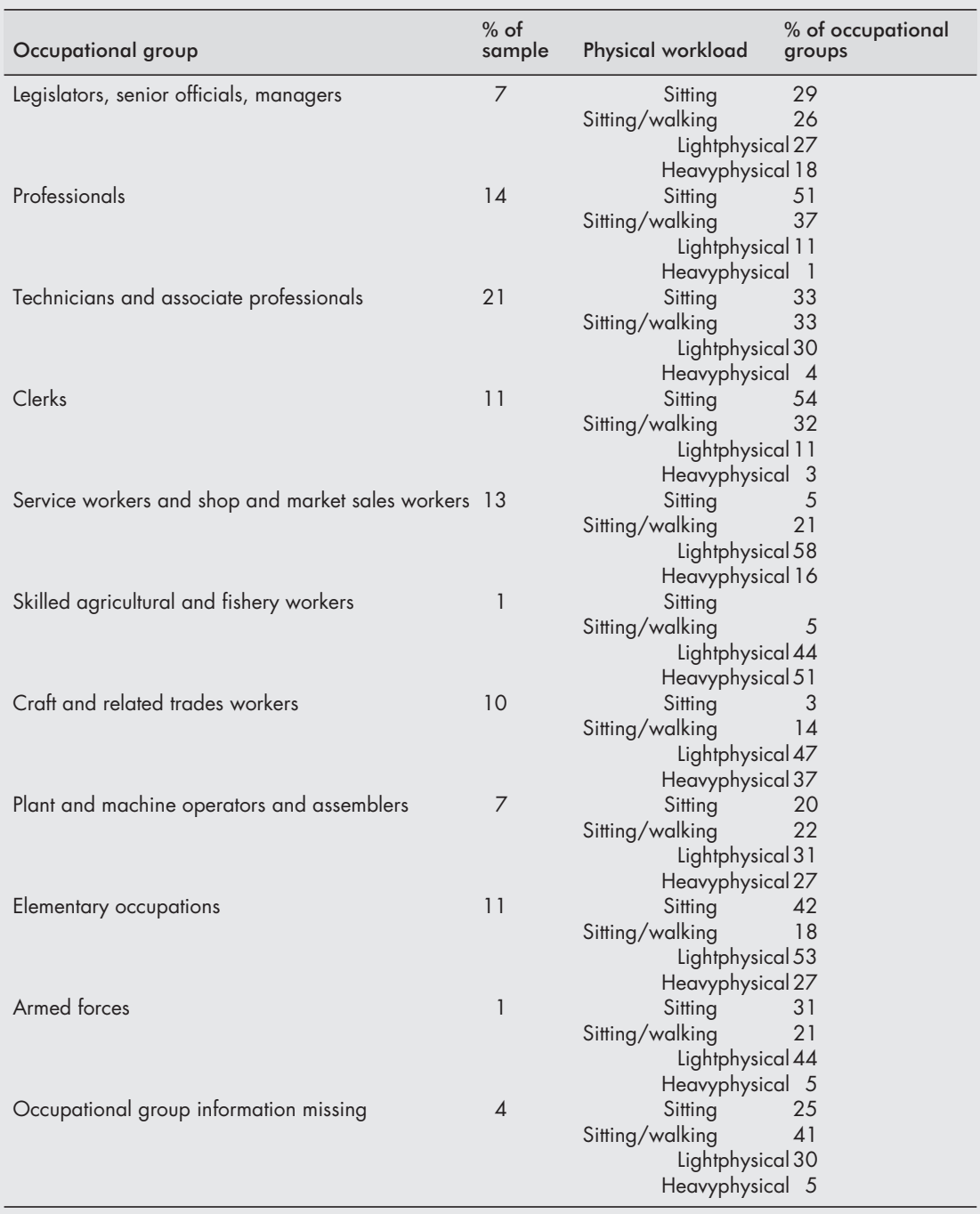


Table 3 Odds ratios with $95 \% \mathrm{Cl}$ for low back pain in relation to physical workload in paired analysis for MZ and DZ twins separately and combined

\begin{tabular}{|c|c|c|c|c|c|c|}
\hline \multirow[b]{2}{*}{ Physical workload } & \multicolumn{3}{|l|}{ LBP short } & \multicolumn{3}{|l|}{ LBP long } \\
\hline & $M Z$ & $\mathrm{DZ}$ & $M Z+D Z$ & $M Z$ & $\mathrm{DZ}$ & $M Z+D Z$ \\
\hline n (cases and controls) & 1122 & 1872 & 2994 & 298 & 528 & 826 \\
\hline $\begin{array}{l}\text { Sitting only } \\
\text { Sitting/walking }\end{array}$ & - & - & - & - & - & - \\
\hline OR & 0.85 & 1.01 & 0.95 & 0.99 & 1.10 & 1.07 \\
\hline $95 \% \mathrm{Cl}$ & 0.63 to 1.14 & 0.80 to 1.27 & 0.80 to 1.14 & 0.58 to 1.69 & 0.77 to 1.54 & 0.79 to 1.44 \\
\hline \multicolumn{7}{|l|}{ Light physical } \\
\hline OR & 1.20 & 1.40 & 1.32 & 1.34 & 1.43 & 1.40 \\
\hline $95 \% \mathrm{Cl}$ & 0.87 to 1.69 & 1.10 to 1.72 & 1.09 to 1.58 & 0.79 to 2.27 & 1.01 to 2.02 & 1.04 to 1.87 \\
\hline \multicolumn{7}{|l|}{ Heavy physical } \\
\hline OR & 0.96 & 1.58 & 1.33 & 2.11 & 2.18 & 2.17 \\
\hline $95 \% \mathrm{Cl}$ & 0.64 to 1.44 & 1.18 to 2.12 & 1.05 to 1.69 & 1.10 to 4.03 & 1.40 to 3.42 & 1.50 to 3.13 \\
\hline \multicolumn{7}{|c|}{ Difference between light and heavy } \\
\hline OR & 0.80 & 1.15 & 1.01 & 1.57 & 1.53 & $1.55^{*}$ \\
\hline $95 \% \mathrm{Cl}$ & 0.55 to 1.54 & 0.88 to 1.50 & 0.81 to 1.25 & 0.94 to 2.62 & 1.02 to 2.29 & 1.33 to 2.13 \\
\hline p value $\dagger$ & 0.14 & $<0.001$ & $<0.001$ & 0.06 & $<0.01$ & $<0.001$ \\
\hline
\end{tabular}

*OR for difference between light and heavy physical work

tp values based on Wald test using physical workload as a categorical/continous variable coded as 1, 2, 3, 4 .

questions relating to the low back were all from the Standardized Nordic Questionnaire. ${ }^{11}$ Possible answers were then grouped into three categories: "no low back pain"; "LBP short", that is, LBP for $\leqslant 30$ days during the past year; and "LBP long", that is, LBP for $>30$ days during the past year.

Physical workload was assessed by asking: "How will you describe your work or daily occupation?". Possible answers were: "sitting", "sitting and walking", "light physical work", and "heavy physical work".

Occupations for this entire twin cohort were coded according to the DISCO-88 classification system developed by the International Labour Organisation. ${ }^{12}{ }^{13}$ Table 2 shows the proportions of twins from discordant pairs in the 10 occupational groups, along with self rated physical work load (table 2).

\section{Twin control method}

The twin control method, or the co-twin control method, is a classic matched case-control design that has several advantages over other matched pair designs. First, twin pairs are genetically matched-that is, MZ twins share $100 \%$ of their genes and DZ twins share roughly $50 \%$. Second, twins are matched closely for a large number of known and unknown environmental factors: they share prenatal environment and they usually share early life environment such as location, socioeconomic background, nutrition, leisure time activities, and possible toxic exposures. Third, twins are of the exact same age and, in this study, also of the same gender.

In a twin-control study twin pairs discordant for a trait or disease are thus used as matched pairs. Analysis is then performed in a way analogous to a case-control study, with the affected twin being treated as the case and the unaffected co-twin as the control.

\section{Zygosity}

Zygosity was determined based on answers to specific questions relating to similarity and mistaken identity. This is a well established and valid method in large twin populations, and comparison with laboratory methods (serological markers) has shown less than $5 \%$ misclassification. ${ }^{14}$

\section{Statistical analysis}

Outcome variables and potential risk indicators (physical workload) were tabulated and checked for logical errors. Incomplete pairs were excluded from further analysis, and because both LBP and physical workload might be gender dependent, opposite sexed DZ twin pairs were also excluded. Paired analyses were then performed using conditional logistic regression, the statistical method of choice in matched designs with categorical data and with more than one level of exposure. ${ }^{15}$ Regression models for the subgroups "LBP short" and "LBP long" were constructed, and odds ratios (OR) with 95\% confidence intervals (CI) were estimated. This was done for MZ and DZ twins separately and combined. Subsequently, to accurately estimate the size of the difference between the light and heavy workload groups, ORs for the difference between the two were computed using the post-estimation command "lincom". To gauge the appropriateness of each model individually, p values for the ORs were computed based on the Wald test, using physical workload as a categorical/continuous variable coded as 1, 2, 3, 4 (table 3); $\mathrm{p}<0.05$ was considered significant. All analyses were performed using the Stata statistical software package, release 6.0 .

\section{RESULTS}

Table 1 describes the study sample with respect to gender, age, LBP, and physical workload. The response rate, after one reminder, was $86.2 \%$.

Table 2 shows proportions of twins in 10 occupational groups according to the DISCO- 88 classification and the distribution of physical workload in the various groups. Twins in the missing category include persons supplying ambiguous or no specific occupational information.

In the paired analysis (table 3, fig 1) a statistically significant positive gradient, or dose-response like relation, was found between physical workload and LBP of more than 30 days duration during the past year, with ORs ranging from 1.07 to 2.17 for MZ and DZ twins combined. For this group both differences between the light and heavy physical group and the Wald test remained significant. Conversely, for LBP of shorter duration no significant difference between light and heavy work was found; in fact ORs and 95\% CIs were practically identical for the two exposures.

For both "LBP short" and "LBP long", no significant differences were found between the sitting only and the sitting/ walking groups, indicating that completely sedentary work and partially sedentary work exhibit an equally neutral effect in relation to LBP.

No significant differences between $\mathrm{MZ}$ and $\mathrm{DZ}$ twins were found in the two groups, even though in the "LBP long" group for DZ twins the difference between light and heavy physical work reached statistical significance. The ORs, however, were practically identical, and with roughly twice the sample size (528 versus 298), the narrower CIs are hardly surprising and probably do not indicate a real difference. 

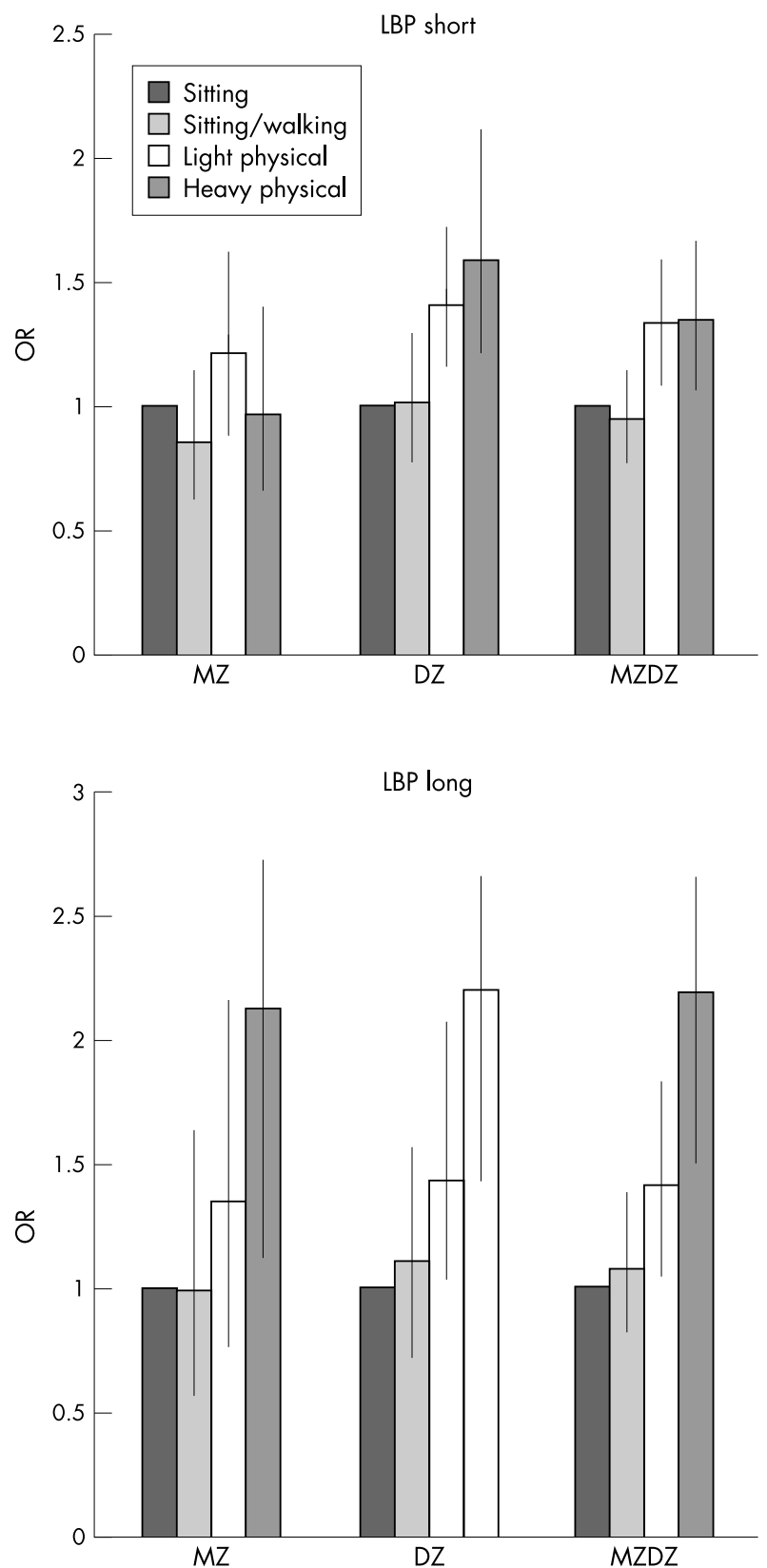

Figure 1 Odds ratios $(95 \% \mathrm{Cl})$ for LBP of $\leqslant 30$ days during the past year (LBP short) and LBP of $>30$ days during the past year (LBP long) for the four workload groups and for MZ and DZ twins separately and combined.

\section{DISCUSSION}

In this study using $3820 \mathrm{MZ}$ and same sexed DZ twin individuals ( 1910 complete pairs) we found a significant positive gradient, or "dose-response" relation, between self reported physical workload and LBP of more than 30 days duration, but not for LBP of shorter duration. Interestingly, the Wald test showed a significant trend between increasing workload and LBP of shorter duration; however the difference between the light and heavy groups was far from significant. Thus we conclude that increasing physical workload is a risk factor for LBP of longer duration but probably not for LBP of shorter duration, implying different causal mechanisms for the two subgroups. Therefore treating LBP as a non-specific entity without attention to clinically relevant subgroups, based on duration, for example, is probably inappropriate in epidemiological studies. ${ }^{16}$

We found no difference with respect to LBP between the group reporting to have only sitting work and the group reporting their work to be both sitting and walking around. This might seem surprising since it has been a common belief that either too little or too much load on musculoskeletal tissues, in this case the lumbar spine, might provoke pain and disability, whereas moderate loads tend to be protective. ${ }^{17}$ In the light of the present findings and two recent systematic reviews, ${ }^{23}$ we question this assumption, at least in relation to LBP.

We further found the OR for MZ and DZ twins to be very similar for all four categories of workload (table 3). However, ORs for MZ and DZ twins were not completely identical (particularly in the "LBP short" group), indicating a possible interaction between genetic and environmental factors. For "LBP long", however, the ORs and 95\% CIs were similar for MZ and DZ twins, indicating that the influence from physical workload on LBP of longer duration might be greater than the genetic influence. Consequently, it will be necessary in future studies on genes and LBP to include physical workload in the statistical models in order not to overestimate the genetic contribution to this condition. This recommendation is in line with findings by Sambrooke and colleagues, ${ }^{18}$ Matsui and colleagues, ${ }^{19}$ and Battié and colleagues ${ }^{20}$ who, using twins to investigate lumbar disc degeneration (but not pain), also found that heaviness of work influenced the heritability estimates significantly. However, to properly address the issue of the relative importance of genetic versus environmental factors in relation to LBP, path analysis using specialised computer software should be used, and this was not the purpose of the present study.

The results of this study should be interpreted in light of several potential limitations. First, twins have to be representative of the normal singleton population for these results to be valid on a larger scale. Indeed the representativeness of twin studies has been questionned. ${ }^{21}$ However twins, in spite of an average lower birth weight, have the same prevalence of many adult diseases, including diabetes mellitus ${ }^{22}$ and thyroid disease ${ }^{23}$; they have the same fecund ability as ordinary siblings, ${ }^{24}$ and the same ischaemic heart disease mortality $^{25}$ and general mortality rate as the general population. ${ }^{26}$ Furthermore the one year period prevalence (46\%) of LBP in this twin sample is comparable to the one year period prevalence (44-54\%) found in other studies from the Nordic countries using population based samples. ${ }^{27}$ Therefore twins are considered to be representative of the general population, ${ }^{8}$ and we found no reason to challenge this assumption.

Second, the definition of LBP has to be valid. To determine validity an accepted gold standard definition of the disease or condition in question is required. Unfortunately, for LBP such a gold standard does not exist at present. This makes the issues of common acceptance and reproducibility important. The LBP definition used in this study is identical to the definition used in the Standardised Nordic Questionnaire. ${ }^{11}$ This is a validated questionnaire and widely used in epidemiological LBP research. The Nordic Questionnaire has been criticised for not being specific in distinguishing between different LBP syndromes. ${ }^{4}$ However, in spite of possible shortcomings, using a commonly accepted and validated questionnaire enables comparison between studies and is normally considered a sign of quality. Also, using a test-retest procedure, Biering-Sorensen and Hilden found the one year recall of LBP using these exact questions to be acceptable. ${ }^{28}$

Third, questionnaire data on physical workload have been criticised for not offering accurate information on exposure. ${ }^{4}$ However, questionnaires do classify groups with heterogeneous occupational tasks, ${ }^{29}$ and questionnaire scores have been 
Main messages

- A statistically significant graded relation exists between physical workload and low back pain of longer duration.

- People sitting down all the time do not experience more low back pain than people who both sit and move around.

- Attention to clinically relevant subgroups is important in epidemiological studies dealing with low back pain.

- Physical workload might more important than genetic factors in low back pain.

\section{Policy implications}

- Programmes aiming at reducing low back pain in the work place should target heavier physical work and not sedentary occupations. shown to be significantly related to current $t^{30}$ and previous ${ }^{31}$ work status. Furthermore, although efforts have been made to better characterise the variability of exposures between and within occupational groups, no consensus has emerged regarding how to precisely measure exposure to physical loads, or how to apply these measurements in real life. ${ }^{32}$ Furthermore, detailed measurements on an individual basis in large samples, such as in this database, are both difficult and very costly if possible at all. The information on occupational group and self reported physical workload presented in table 2 adds credibility to our exposure information given detailled knowledge of this classification system and the specific occupations included in each group. ${ }^{13}$

The present study was nested in a large general health survey. Thus LBP was not singled out to the participants as the aim of the questionnaire or any subsequent study, and bias arising from attention to any one health problem, in this case LBP, was probably avoided. In addition the high response rate $(86.2 \%)$ ensures representativeness of this sample. Our results, using a research design not used previously to investigate workload as a risk factor for LBP, confirms the results of two recent systematic reviews in this area. ${ }^{2}{ }^{3}$ Furthermore it is in line with the results of Bengtsson and Thorson, who, in the only previous study dealing specifically with LBP and workload in twins, found the proportion of both MZ and DZ twins with "back pain" significantly higher in the "heavy work" group compared to the "light work" group. ${ }^{33}$

Longitudinal studies are needed to study the long term effects of various workloads in this cohort, and to better study interactions between genetic and environmental factors, such as physical workload or other occupational exposures, and LBP. Some workers, for example, are able to tolerate heavy physical work for many years, whereas others have very limited tolerance and move on to other types of jobs, the so called "healthy worker" effect. Much of the variation in response to seemingly identical exposures could possibly be explained by interactions between the environment, in this case physical workload, and the genetic make-up of the individual. Studies aiming at identifying such interactions are currently being undertaken at the Danish Twin Register.

\section{ACKNOWLEDGEMENTS}

The authors greatfully acknowledge professor Werner Vach, Dept of Demographics and Biostatistics, University of Southern Denmark, for statistical advice. The principal author was assisted by funding from The Foundation for Chiropractic Research and Postgraduate Education.

\section{Authors' affiliations}

J Hartvigsen, Nordic Institute of Chiropractic and Clinical Biomechanics, Klosterbakken 20, DK-5000 Odense C, Denmark

K O Kyvik, L Bakketeig, University of Southern Denmark, Institute of

Public Health, The Danish Twin Register, Sdr. Boulevard 23A, DK-5000

Odense C, Denmark

C Leboeuf-Yde, The Medical Research Unit in Ringkiøbing County,

Torvet 1, DK-6950 Ringkøbing, Denmark

S Lings, Odense University Hospital, Dept of Occupational and

Environmental Medicine, Sdr. Boulevard 29, DK-5000 Odense C,

Denmark

\section{REFERENCES}

1 Maniadakis N, Gray A. The economic burden of back pain in the UK. Pain 2000;84:95-103.

2 Hoogendoorn WE, van Poppel MN, Bongers PM, et al. Physical load during work and leisure time as risk factors for back pain. Scand J Work Environ Health 1999;25:387-403.

3 Hartvigsen J, Leboeuf-Yde C, Lings $S$, et al. Is sitting-while-at-work bad for your low back? A systematic, critical literature review. Scand J Public Health 2000;28:230-9.

4 Riihimäki $\mathbf{H}$. Hands up or back to work-future challenges in epidemiologic research on musculoskeletal diseases. Scand J Work Environ Health 1995;21:401-3.

5 Borkan JM, Koes B, Reis S, et al. A report from the Second International Forum for Primary Care Research on Low Back Pain. Reexamining priorities. Spine 1998;23:1992-6.

6 Leboeuf-Yde C, Manniche C. Low back pain: time to get off the treadmill. J Manipulative Physiol Ther 2001;24:63-6.

7 Leboeuf-Yde C, Kyvik KO, Bruun NH. Low back pain and lifestyle, II: obesity-information from a population-based sample of 29,424 twin subjects. Spine 1999;24:779-84.

8 Kyvik KO. Generalisability and assumptions of twin studies. In: Spector TD, Snieder H, MacGregor AJ, eds. Advances in twin and sib-pair analysis. London: Greenwich Medical Media Ltd, 2000:67-78.

9 Duffy DL. The co-twin control study. In: Spector TD, Snieder H, MacGregor AJ, eds. Advances in twin and sib-pair analysis. London: Greenwich Medical Media Ltd, 2000:53-66.

10 Kyvik KO, Green A, Beck-Nielsen H. The New Danish Twin Register: establishment and analysis of twinning rates. Int J Epidemio 1995;24:589-96

11 Kuorinka IA, Jonsson B, Kilbom A, et al. Standardized Nordic Questionnaires for the analysis of musculoskeletal symptoms. Appl Ergon 1987; 18:233-7.

12 DISCO-88. Statistics Denmark's Standard Classification of Occupations. Copenhagen: Danmarks Statistik, 1996.

13 Hartvigsen J, Lings S, Corder EH. Coding of occupation for the "young cohort" of the Danish Twin Register. Scand J Public Health 1999;2:148-51.

14 Hauge $M$. The Danish Twin Register. In: Mednick SA, Baert AE, Bachmann BP, eds. Prospective longitudinal research: an empirical basis for the primary prevention of psychosocial disorders. Oxford: Oxford University Press, 1981:217-21.

15 Holford TR, White C, Kelsey JL. Multivariate analysis for matched case-control studies. Am J Epidemiol 1978;107:245-56.

16 Leboeuf-Yde C, Lauritsen JM, Lauritzen T. Why has the search for causes of low back pain largely been nonconclusive? Spine 1999:22:877-81.

17 Winkel J. On the significance of physical activity in sedentary work. In: Knave B, Wickback PG, eds. Work with display units 86. Amsterdam Elsevier Science Publishers BV, 1986:229-36.

18 Sambrook PN, MacGregor A, Spector TD. Genetic influences on cervical and lumbar disc degeneration: a magnetic resonance imaging study in twins. Arthritis Rheum 1999;42:366-72.

19 Matsui H, Tsuji H, Terahata N. Juvenile lumbar herniated nucleus pulposus inmonozygotic twins. Spine 1990;15:1228-30.

20 Battié MC, Haynor DR, Fisher LD, et al. Similarities in degenerative findings on magnetic resonance images of the lumbar spines in identical twins. J Bone Joint Surg 1995;77-A: 1662-70.

21 Phillips DI. Twin studies in medical research: can they tell us whether diseases are genetically determined? Lancet 1993;341:1008-9.

22 Kyvik KO, Green A, Beck-Nielsen H. Concordance rates of insulin dependent diabetes mellitus: a population based study of young Danish twins. BM 1995;311:913-17.

23 Brix TH, Hansen PS, Kyvik KO, et al. Cigarette smoking and risk of clinically overt thyroid disease: a population-based twin case-control study. Arch Intern Med 2000;160:661-6.

24 Christensen $\mathrm{K}$, Basso O, Kyvik KO, et al. Fecund ability of female twins. Epidemiology 1998;9:189-92.

25 Vagero $D$, Leon $D$. Ischaemic heart disease and low birth weight: a test of the fetal-origins hypothesis from the Swedish Twin Registry. Lance 1994;343:260-3

26 Christensen K, Vaupel JW, Holm NV, et al. Mortality among twins after age 6: fetal origins hypothesis versus twin method. BM 1995;310:432-6.

27 Leboeuf-Yde C, Klougart N, Lauritzen T. How common is low back pain in the Nordic population? Data from a recent study on a middle-aged Danish population and four surveys conducted in the Nordic countries. Spine 1996;21:1518-25. 
28 Biering-Sorensen F, Hilden J. Reproducibility of the history of low-back trouble. Spine 1984;9:280-6

29 Viikari-Juntura E, Rauas S, Martikainen R, et al. Validity of self-reported physical work load in epidemiologic studies on musculoskeletal disorders. Scand J Work Environ Health 1996;22:251-9.

30 Loisel P, Poitras S, Lemaire J, et al. Is work status of low back pain patients best described by an automated device or by a questionnaire? Spine 1998;23:1588-94
31 Torgen M, Winkel J, Alfredsson L, et al. Evaluation of questionnaire-based information on previous physical work loads. Scand J Work Environ Health 1999;25:246-54.

32 Kauppinen T. Exposure assessment-a challenge for occupational epidemiology. Scand J Work Environ Health 1996;22:401-3.

33 Bengtsson B, Thorson J. Back pain: a study of twins. Acta Genet Med Gemellol (Roma) 1991;40:83-90.

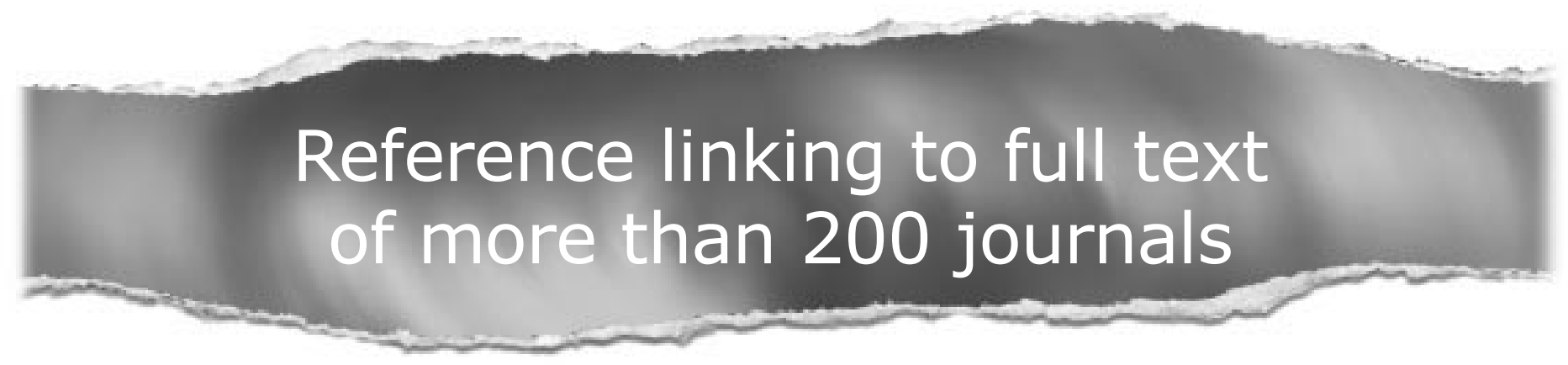

Toll free links

You can access the FULL TEXT of articles cited in Occupational and Environmental Medicine online if the citation is to one of the more than 200 journals hosted by HighWire (http://highwire.stanford.edu) without a subscription to that journal.

There are also direct links from references to the Medline abstract for other titles.

www.occenvmed.com 